\title{
SUY THOÁI ĐÂT ĐAI Ở VIẸTT NAM: THỰC TRẠNG VÀ GIẢI PHÁP
}

\author{
Lê Đỗ Mai Anh, Đỗ Kiều Anh, Phan Thị Mai Anh, Hoàng Tài An, \\ Nguyễn Ngọc Minh Anh, Lê Thị Tuyết Anh, Nguyễn Trần Hiệp, Kiều Thị \\ Ngọc Ánh, Phạm Vân Anh, Lê Vinh Khánh, Nguyễn Thanh Bình
}

Đại học quốc gia Hà Nội

Ngày 05 tháng 01 năm 2022

\section{Preprints DOI: https://osf.io/9bxrs}

Đất đai đóng vai trò không thể thiếu trong cuộc sống của con người cũng như động, thực vật. Qua thời gian, đất đai chịu ảnh hưởng bởi các hoạt động sống của con người dẫn đến tình trạng suy thoái. Hiện tượng thoái hóa đất đang xảy ra rất phổ biến do con người gây nên qua việc phá rừng bừa bãi, thiếu chiến lược khai thác trên quan điểm bảo vệ đất và bảo vệ môi trường sinh thái, du canh, du cư... Sự thoái hóa đất biểu hiện ở các hiện tượng xói mòn, rửa trôi, suy thoái hóa học, suy thoái vật lý, sinh học. Không chỉ riêng gì Việt Nam mà các quốc gia trên thế giới đều đang đứng trước thách thức rất lớn với vấn đề ô nhiễm môi trường đất vì nó đe dọa đến môi trường sống của rất nhiều loại sinh vật (Q.H. Vuong, 2021).

Theo nghiên cứu của các nhà khoa học, lớp đất mặt đang có nguy cơ bị biến mất một phần trong tương lai. Liên Hợp Quốc cũng đưa ra cảnh báo, khoảng $1 / 3$ tài nguyên đất trên hành tinh đang bị suy thoái do xói mòn, ô nhiễm, quá trình axit hóa và suy giảm chất dinh dưỡng. Nguyên nhân chủ yếu của tình trạng này là do quá trình quản lý đất chưa tốt của con người. Tác nhân lớn nhất của tình trạng này bắt nguồn từ văn hóa của con người (Van Khuc et al., 2021; Q. H. Vuong, 2021; Q. H. et al. Vuong, 2018), đó là việc con người "vắt kiệt sức" làm việc của đất để sản xuất nông nghiệp. Việc trồng cây lương thực để sản xuất nhiên liệu sinh học, biến đối khí hậu và những biện pháp canh tác đơn giản đang làm tăng nguy cơ thiếu lương thực trong tương lai. Bên cạnh đó, còn có những nguyên nhân trực tiếp làm suy thoái đất khác bao gồm tình trạng đô thị hóa, phát triển cơ sở hạ tầng, sản xuất năng lượng, khai khoáng...(Bộ Tài nguyên và Môi trường, 2019), ngoài ra còn có nhiều nguyên nhân khác dẫn đển việc đất đai bị suy thoái bao gồm cả tự nhiên lẫn con người:sóng thần, động đất, bão, lũ, chặt đốt rừng, mất rừng và suy thoái rừng (Khuc et al., 2018), canh tác lạc hậu không hiệu quả, lạm dụng các chất hóa học,..Ô nhiễm đất gây ảnh hưởng nghiêm trọng tới sức khỏe, đời sống con người thông qua đường hô hấp, ngoài ra nó còn ảnh hưởng một phần không nhỏ tới hệ sinh thái làm suy giảm đa dạng sinh học, gây hậu quả nghiêm trọng cho trái đất và loài người. 


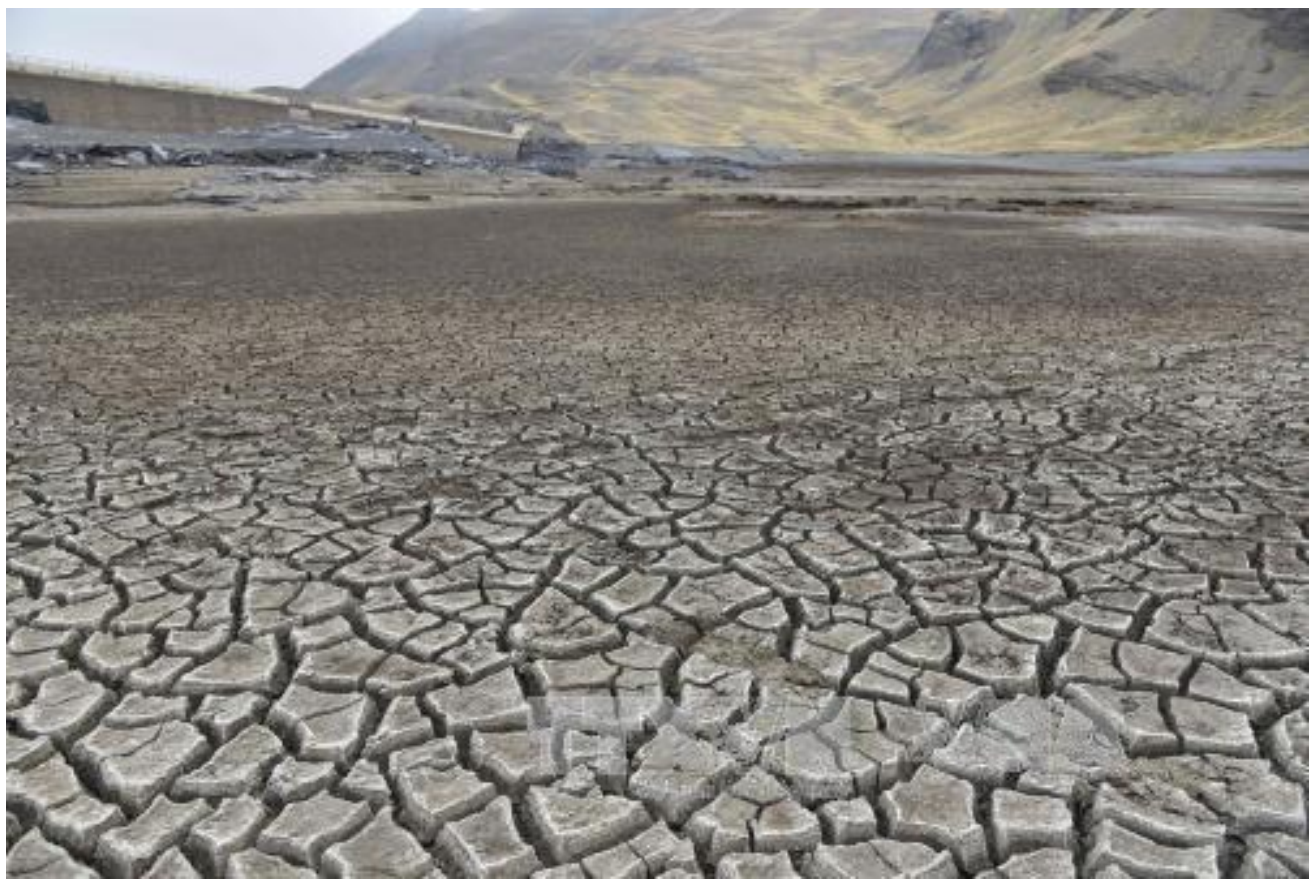

Cảnh khô hạn tại hồ chứa nước Ajuankota ở thủ đô La Paz, Bolivia ngày 21/11 Nguồn: AFP/TTXVN

https://www.thiennhien.net/2018/06/18/phuc-hoi-dat-suy-thoai-truoc-khi-qua-muon/

Theo các số liệu thống kê, tổng diện tích đất tự nhiên của Việt Nam là 33 triệu ha, trong đó 26,1 triệu ha đất cho nông nghiệp, lâm nghiệp và nuôi trồng thủy sản, 3,7 triệu ha sử dụng cho các mục đích phi nông nghiệp và 3,3 triệu ha còn lại chưa được đưa vào vào sử dụng. Thế nhưng đáng chú ý ở đây là hầu hết các khu vực không được sử dụng đã bị ô nhiềm, bị xuống cấp, sa mạc hóa hoặc đã mất giá trị do khai thác bất hợp lý quá mức. Trong tình hình dân số ngày càng tăng và sự phát triển mạnh mẽ của các khu đô thị,khu công nghiệp mới một khu vực rộng lớn của quỹ đất phi nông nghiệp và nông nghiệp đã bị ô nhiễm nghiêm trọng (Báo Nỡ Yêu, 2021).

Việt Nam có tới 9,34 triệu ha đất bị hoang hóa, tuy nhiên trong đó có khoảng 7,85 triệu ha chịu tác động mạnh do sa mạc hóa gây ra, phần lớn là đất trống, đồi núi bạc màu, có nguy cơ bị thoái hóa nghiêm trọng. ... Đất khô hạn đang chiếm tới $43 \%$ diện tích đất canh tác của thế giới (Sfarm.vn, 2018). Tài nguyên rừng cũng bị suy giảm một cách đáng kể, nếu vào năm 1943 nước ta có tỷ lệ rừng che phủ là $43 \%$ thì sau nhiều nỗ lực khắc phục các tình trạng mất rừng trong suốt 60 năm qua, tỷ lệ rừng che phủ hiện nay mới chỉ là $37,6 \%$ (Tháng 12-2006). Rừng bị mất làm tăng diện tích đất hoang hóa, kéo theo đó là sự suy giảm đáng kể của các hệ sinh thái, làm suy thoái vùng đầu nguồn.

Nguyên nhân là do lãnh thổ nước ta có độ dốc cao; lượng dòng chảy phong phú, tốc độ lớn; cây trồng cạn theo phương pháp quảng canh lâu dài, đốt rừng làm nương rẫy, nhất là rừng đầu nguồn không có thảm thực vật che phủ, xói mòn đất, rửa trôi chất hữu cơ mà không có biện pháp bồi dưỡng, bổ sung hữu cơ cho đất (mekongfarm, 2018). Ô nhiễm đất 
do sử dụng nhiều loại nông dược với số lượng lớn để bảo vệ chất lượng và số lượng cây trồng, nhiều rác thải, nước thải sinh hoạt và công nghiệp; nhiễm mặn; nhiễm độc từ các chế phẩm hóa học... đất đai dần bị thoái hóa (Hùng Chaetomium, 2019). Ô nhiễm từ hoạt động công nghiệp, khai thác mỏ, canh tác và quản lý chất thải chưa chặt chẽ. Các chất gây ô nhiễm bao gồm kim loại, xyanua, DDT và các loại thuốc trừ sâu khác; PCB...

\begin{tabular}{|c|c|c|c|c|c|}
\hline \multirow[b]{2}{*}{$\begin{array}{l}\text { Loại hình sữ dụng } \\
\text { đất }\end{array}$} & \multirow[b]{2}{*}{$\begin{array}{c}\text { Diện } \\
\text { tích } \\
\left(\mathrm{km}^{2}\right)\end{array}$} & \multicolumn{4}{|c|}{ Mức độ suy thoái đất $\left(\mathrm{km}^{2}\right)$} \\
\hline & & $\begin{array}{l}\text { Suy } \\
\text { thoái }\end{array}$ & $\begin{array}{c}\text { Có dấu } \\
\text { hiện suy } \\
\text { thoái }\end{array}$ & $\begin{array}{l}\text { Có nguy } \\
\text { cơ bị suy } \\
\text { thoái }\end{array}$ & $\begin{array}{c}\text { Ít nguy } \\
\text { cơ bị suy } \\
\text { thoái }\end{array}$ \\
\hline Đất lâm nghiệp & 140.288 & 1.258 & 10.448 & 32.397 & 63.345 \\
\hline $\begin{array}{l}\text { Cây bụi, đất có cỏ và } \\
\text { cây rài rác }\end{array}$ & 32.814 & 514 & 2.732 & 7.565 & 10.957 \\
\hline Canh tác nông nghiệp & 72.354 & 8.462 & 6.320 & 15.514 & 32.965 \\
\hline Đất ngập nước & 39.434 & 1.350 & 3.539 & 8.726 & 11.150 \\
\hline Khu vực dân cư & 44.372 & 1.488 & 944 & 2.748 & 5.363 \\
\hline Tỷ lệ (\%) & & 4,0 & 7,3 & 20,3 & 38,0 \\
\hline Tổng $\left(\mathrm{km}^{2}\right)$ & 329.263 & 13.072 & 23.982 & 66.950 & 123.781 \\
\hline
\end{tabular}

Thực trạng suy thoái đất trên phạm vi toàn quốc. Nguồn: Báo nông nghiệp Việt Nam https://nongnghiep.vn/ca-nuoc-co-13-trieu-ha-dat-bi-suy-thoai-d243456.html

Đứng trước nguy hại to lớn do hậu quả của suy thái đất đai gây nên GEF (Quỹ Môi trường toàn cầu) chống lại sự suy thoái đất tập trung vào việc quản lý đất đai bền vững (SLM) vì sự suy thoái đất chủ yếu liên quan đến sa mạc hóa và phá rừng. GEF cho rằng các hoạt động nông nghiệp không bền vững cùng với xói mòn đất, chăn thả quá mức, phá rừng,... là những nguyên nhân chính gây thoái hóa đất, tất cả góp phần làm suy giảm các dịch vụ sinh thái. Quỹ môi trường toàn cầu giải quyết thực trạng suy thoái đất bằng cách giải quyết các nguyên nhân chính song song đó tìm ra các giải pháp bền vững. GEF cũng tập trung vào việc quản lý tài nguyên thiên nhiên trong bối cảnh cảnh quan rộng lớn hơn, cho phép các khoản đầu tư tập trung vào quản lý hiệu quả các hình thức sử dụng đất cạnh tranh, hoàn dịch vụ hệ sinh thái, các cơ hội để tăng cường đầu tư trong SLM qua các nguồn khác nhau như: chi trả dịch vụ hệ sinh thái (PES), tài chính carbon, v.v... (Quỹ môi trường toàn cầu Việt Nam, 2018), không chỉ cần sự nỗ lực của các tổ chức thế giới mà còn cần sự ý thức chung tay của tất cả mọi người để ngăn chặn thoái hóa đất:xaay dựng hệ thống tưới tiêu và kỹ thuật tưới nước hợp lý, tuy nhiên giải pháp này không phải nơi nào cũng áp dụng được vì nhiều nơi các kỹ thuật, máy móc còn lạc hậu, chưa ứng dụng có hiệu quả trong việc bảo vệ đất thoái hóa. Hay như trồng cây, bảo vệ rừng, tuy nhiên cây cối phải mất vài năm mới có thể to lớn đủ sức để giữ đất và chống xói mòn do lũ gây ra nhưng bên cạnh đó con người vẫn khai thác cây lấy gỗ dẫn đến tiến độ trồng cây không theo kịp tiến độ chặt 
cây. Con người đã đưa ra hàng loạt các giải pháp ứng dụng vào đời sống nhằm nâng cao chất lượng đất đai tuy nhiên vẫn có nhiều giải pháp chưa thực sự hiệu quả và triệt để dẫn đến tình trạng thoái hóa đất vẫn còn diễn ra ngày một nhiều ở một số nơi, nhất là những nơi đông dân cư và kỹ thuật chăm sóc đất nghèo nàn.

Các hệ thống nông nghiệp cơ bản là động lực chính gây suy thoái đất và môi trường và là nguồn đáng kể phát thải khí nhà kính sinh học chính. Cày bừa, thực hành nông nghiệp không phù hợp, kết hợp với phá rừng và chăn thả quá mức, là những nguyên nhân chính gây ra xói mòn đất do con người gây ra.Trong khi nhiều nghiên cứu tập trung vào nông nghiệp canh tác, trong một bài báo gần đây, người ta đã chứng minh rằng không thể bỏ qua các hệ thống nguyên sinh, có thể là nguyên nhân dẫn đến phần lớn xói mòn đất toàn cầu do nước (Borrelli et al., 2020).

Tuy nhiên, động lực cơ bản của tất cả những thay đổi này là bình quân đầu người ngày càng tăng do dân số ngày đông dẫn đến nhu cầu đối với protein, chất xơ và năng lượng sinh học cũng tăng dần từ đó. Điều này dẫn đến những đòi hỏi, nhu cầu nhiều hơn về đất đai và sự xâm lấn sâu hơn vào các khu vực có đất ven biên.

Ngoài ra, phi điều tiết thị trường, vốn là một xu hướng toàn cầu từ những năm 1980 , có thể dẫn đến phá hủy các phương thức quản lý đất đai bền vững theo hướng độc canh, và có thể khuyến khích cuộc chạy đua xuống đáy khi có liên quan đến bảo vệ môi trường. Khoảng cách địa lý rộng lớn giữa nhu cầu về hàng hóa tiêu dùng và đất đai cần thiết để sản xuất chúng - hay nói cách khác đây cũng chính là nguyên nhân gây ra suy thoái đất và ảnh hưởng của nó đến môi trường. (Abbas El-Zein, 2018).

Sử dụng hệ xử lý thông tin 3D (Q. H. Vuong \& Napier, 2014) và nguyên lý bán dẫn để tìm các giải pháp sáng tạo hiệu quả là chìa khóa cho vấn đề môi trường nói chung và suy thoái đất nói riêng (Khuc, 2022; Q. H. Vuong, 2021).

Thứ nhất, bảo tồn đất là việc làm cần thiết và cấp bách nhằm ngăn ngừa mất lớp trên cùng của đất khỏi xói mòn, ngăn chặn sự giảm độ phì nhiêu trong tình trạng thoái hóa đất đáng báo động như hiện nay.

Thứ hai, cần phải nỗ lực quản lý rừng và có kế hoạch tái trồng rừng như nạn phá rừng ở Paraguay được cho là đã giảm $65 \%$ trong vòng hai năm kể từ khi ban hành Luật Không phá rừng năm 2004. Nên kiềm chế chăn nuôi công nghiệp (Curb industrial farming), hạn chế cày xới đất, để cho đất nghỉ. (Phạm Văn Đồng, 1964).

Thứ ba là làm đa dạng sinh vật đất, thực hiện các biện pháp khoáng hóa tích cực cũng như tăng cường sử dụng phân ủ hữu cơ cho đất canh tác và bảo vệ đất, phải thay đổi các hoạt động của con người như: tập quán canh tác, chăn thả gia súc, khai thác khoáng sản bừa bãi ,... (Phạm Văn Đồng, 1964).

Thứ tư, dù là rác thải công nghiệp hay rác thải sinh hoạt, xử lý rác thải hiệu quả là một trong những cách hiệu quả nhất để hạn chế ô nhiễm đất, giảm việc sử dụng các vật liệu 
không phân hủy sinh học, chỉ cần chuyển sang túi vải có thể tái sử dụng, từ đó giảm thiểu rác thải nhựa ra môi trường, gián tiếp bảo về đất (Phạm Văn Đồng, 1964).

Cuối cùng, giáo dục là chìa khóa để giảm thiểu vấn đề ô nhiễm đất, chúng ta cần phải cho mọi người thấy những tác động xấu từ hành động của chúng ta đến việc suy thoái đất đai. Cần xây dựng gấp những quy định cụ thể và thiết thực hơn nữa trong: lựa chọn đất canh tác, khai hoang, trồng trọt, bón phân, xây dựng những công trình giữ nước và giữ màu đất cho thích hợp với từng vùng miền. (Phạm Văn Đồng, 1964).

\section{TÀI LIỆU THAM KHẢO:}

Abbas El-Zein. (2018). On dangerous ground: land degradation is turning soils into deserts. The Conversation. https://theconversation.com/on-dangerous-ground-landdegradation-is-turning-soils-into-deserts94100?fbclid=IwAR2E6Fb8v1 yhNnb7_IFvuQRH3i5lBFtsd8pczcWP0heWR_jyKN 8V3lUqhsI

Báo Nỡ Yêu. (2021). Thực trạng ô nhiếm môi truờng đất ở Việt Nam. Nỡ Yêu. https://noyeu.com/thuc-trang-o-nhiem-moi-truong-dat-o-viet-nam/

Bộ Tài nguyên và Môi trường. (2019). Vắt kiệt sức đất. Monre.Gov. https://monre.gov.vn/Pages/vat-kiet-suc-dat.aspx

Borrelli, P., Robinson, D. A., Panagos, P., Lugato, E., Yang, J. E., Alewell, C., Wuepper, D., Montanarella, L., \& Ballabio, C. (2020). Land use and climate change impacts on global soil erosion by water (2015-2070). Proceedings of the National Academy of Sciences of the United States of America, 117(36), 21994-22001. https://doi.org/10.1073/pnas.2001403117

Hùng Chaetomium. (2019). 3 nguyên nhân chính khiến đất trồng bị suy thoái. https://nongnghiepthuanthien.vn/3-nguyen-nhan-chinh-khien-dat-trong-bi-suythoai/?fbclid=IwAR2PskmIQRQKjE49sSU6UbbnnnNgXbH4TcyDS5VH0Zk2UYM9t09jViuFbs

Khuc, Q. Van. (2022). Về khả năng ứng dụng của hệ xử lý thông tin 3D và nguyên lý bán dẫn giá trị trong tìm kiếm giải pháp cho vấn đề ô nhiễm môi trường và biến đổi khí hậu ở Việt Nam. Tạp Chí Kinh Tế và Dư Báo, 1, 1-5. https://kinhtevadubao.vn/vekha-nang-ung-dung-cua-he-xu-ly-thong-tin-3d-va-nguyen-ly-ban-dan-gia-tri-trongtim-kiem-giai-phap-cho-van-de-o-nhiem-moi-truong-va-bien-doi-khi-hau-o-vietnam-20840.html

Khuc, Q. Van, Tran, B. Q., Meyfroidt, P., \& Paschke, M. W. (2018). Drivers of deforestation and forest degradation in Vietnam: An exploratory analysis at the national level. Forest Policy and Economics, 90(February), 128-141. https://doi.org/10.1016/j.forpol.2018.02.004 
mekongfarm. (2018). Nguyên nhân của sự toái hóa đất do con người gây nên.

Mekongfarm. http://mekongfarm.vn/tin-tuc/24/nguyen-nhan-cua-su-thoai-hoa-datdo-con-nguoi-gay-

nen?fbclid=IwAR3LYcpsAUJL3xJ3TSRzDjckVDZfyOAHQ7PZBL5oOppiaaNvtw637xS5VU

Phạm Văn Đồng. (1964). Chỉ thị 15-TTG ngày 11/02/1964 về chống xói mòn, giư đất, giũa mầu, giữ nuớc do thủ tuớng chính phủ ban hành.

https://thuvienphapluat.vn/van-ban/Tai-nguyen-Moi-truong/Chi-thi-15-TTg-chongxoi-mon-giu-dat-giu-mau-giu-nuoc-

19672.aspx?fbclid=IwAR1KYCOp19v9KPckSOl4jq1oyFvfO84214RqcGcyKaNRZW8jjeQ-ilCAbE

Quỹ môi trường toàn cầu Việt Nam. (2018). Hoạt động suy thoái toàn cầu. Gef. https://www.gef.monre.gov.vn/vi/linh-vuc-trong-tam/suy-thoai-dat/hoat-dong-suythoai-dat-toan-cau/

Sfarm.vn. (2018). Đất trồng bị thoái hóa: thực trạng, nguyên nhân, giải pháp. Sfarm. https://sfarm.vn/dat-trong-bi-thoai-hoa-thuc-trang-nguyen-nguyen-nhan-va-giaiphap/?fbclid=IwAR2BRSQG7Mi2AVYA11YUEJllaGtTHVB1Q3P4wNM1i4gcxIuPkOXCkz5AcI

Van Khuc, Q., Pham, L., Tran, M., Nguyen, T., Tran, B. Q., Hoang, T., Ngo, T., \& Tran, T. D. (2021). Understanding vietnamese farmers' perception toward forest importance and perceived willingness-to-participate in redd+ program: A case study in nghe an province. Forests, 12(5), 1-14. https://doi.org/10.3390/f12050521

Vuong, Q.-H. (2021). Western monopoly of climate science is creating an eco-deficit culture. Economy, Land \& Climate Insight, 11, 1-9. https://elc-insight.org/westernmonopoly-of-climat

Vuong, Q. H. (2021). The semiconducting principle of monetary and environmental values exchange. Economics and Business Letters, 10(3), 284-290.

https://doi.org/10.17811/ebl.10.3.2021.284-290

Vuong, Q. H. et al. (2018). Cultural additivity: behavioural insights from the interaction of Confucianism, Buddhism and Taoism in folktales. Palgrave Communications, 4(143). https://doi.org/10.1057/s41599-018-0189-2

Vuong, Q. H., \& Napier, N. K. (2014). Making creativity: the value of multiple filters in the innovation process. International Journal of Transitions and Innovation Systems, 3(4), 294-327. https://doi.org/10.1504/ijtis.2014.068306 